\title{
ANALISIS HUBUNGAN COST EFECTIVENESS MAHASISWA PENGHUNI ASRAMA DENGAN PRESTASI BELAJAR
}

\author{
Vira Maratus Sholihah ${ }^{1}$, Mukhamad Zulfikar Lutfi², Asep Sunandar ${ }^{3 *}$, \\ Maulana Amirul Adha ${ }^{4}$ \\ Jurusan Administrasi Pendidikan Fakutas Ilmu Pendidikan Universitas Negeri Malang \\ Email:virasholihah24@gmail.com ${ }^{1}$,zzulfikarlutfi87@gmail.com ${ }^{2}$, \\ asep.sunandar.fip@um.ac.id ${ }^{3 *}$,amirulmaulana1013@gmail.com ${ }^{4}$
}

\begin{abstract}
Abstrak
Penelitian ini bertujuan untuk, (1) mengetahui analysis cost effectiveness mahasiswa penghuni asrama yang ada di fakultas-fakultas lingkungan Universitas Negeri Malang (UM); (2) mengetahui prestasi belajar mahasiswa di fakultas-fakultas lingkungan UM; dan (3) mengetahui hubungan analysis cost effectiveness mahasiswa penghuni asrama terhadap prestasi belajar di fakultas-fakultas lingkungan UM. Penelitian ini menggunakan pendekatan kuantitatif dengan rancangan penelitian bersifat deskriptif korelasional. Instrumen penelitian ini menggunakan bantuan survey google form dengan responden mahasiswa penghuni asrama di fakultasfakultas lingkungan UM. Teknik analisis yang digunakan dalam penelitian ini ialah analisis deskriptif dan korelasi. Hasil penelitian ini menunjukkan: (1) tingkat analysis cost effectiveness penghuni asrama mahasiswa yang berada di fakultas-fakultas lingkungan Universitas Negeri Malang tergolong jarang yang menggunakan analisis efektifitas biaya dalam mengatur keuangan untuk keperluan asrama dan pendidikannya; (2) tingkat prestasi belajar yang tersebar di semua fakultas yang ada di Universitas Negeri Malang cenderung kurang baik; dan (3) hasil penelitian menunjukkan bahwa ada hubungan antara analysis cost effectiveness penghuni asrama mahasiswa UM terhadap prestasi belajar.
\end{abstract}

Kata Kunci: mahasiswa, prestasi, asrama, perguruan tinggi

\begin{abstract}
This study aims (1) to determine the cost effectiveness analysis of students' dormitory which lies in the faculties of the State University of Malang (UM); (2) to know students' achievement in UM environment faculties; and (3) to know the relationship between cost effectiveness analysis of UM students' dormitory and the study achievement in UM faculties. This research uses a quantitative approach with a descriptive correlational research design. The instrument of this study used the Google form survey assistance with respondents are students of UM dormitory in UM environmental faculties. The analysis technique used in this research is descriptive analysis and correlation. The results of this study indicate: (1) the level of cost effectiveness analysis of the occupants of UM students' dormitory residing in the faculties of the State University of Malang is classified as a rarity that uses cost effectiveness analysis in managing finances for dormitory and educational needs; (2) the level of learning achievement that is spread in all faculties at the State University of Malang tends to be poor; and (3) the results of the study show that there is a relationship between cost effectiveness analysis of UM student dormitory students on learning achievement.
\end{abstract}

Keywords: student, achievement, boarding, higher education 


\section{PENDAHULUAN}

Pendidikan merupakan salah satu proses dalam mempengaruhi peserta didik untuk menyesuaikan peserta didik dengan lingkungannya. Alternatif dalam layanan pendidikan yang ditawarkan untuk menghasilkan SDM berkualitas yaitu asrama pada Perguruan Tinggi ${ }^{1}$. Asrama dalam perguruan tinggi sangatlah penting untuk mahasiswa perantau yang tempat tinggalnya jauh dari kampus dan bahkan dari luar daerah atau pulau. Mereka pastinya akan mencari hunian yang nyaman dan aman untuk mereka tinggali. Keberadaan asrama dengan kampus sangat melekat pada lembaga pendidikan. Asrama diartikan sebagai bangunan tempat tinggal bagi sekelompok orang untuk sementara waktu².

Asrama memiliki jumlah kamar yang cukup dan banyak serta dalam kepengurusannya asrama dipimpin oleh kepala asrama atau kepala pengurus asrama. Sementara menurut Roche ${ }^{3}$ asrama diartikan sebagai sebuah lingkungan bangunan atau rumah yang berfungsi sebagai tempat tinggal mahasiswa, dalam perkembangan lebih lanjut, dimungkinkan memiliki sarana lingkungan untuk melengkapinya, seperti perpustakaan, pengadaan buku, kantin, olah raga dan sarana lainnya yang diperlukan yang dikelola oleh mahasiswa dalam bentuk koperasi atau kantin dalam asrama.

Salah satu indikator keberhasilan pendidikan di suatu perguruan tinggi terletak pada pencapaian prestasi mahasiswa ${ }^{4}$. Prestasi belajar merupakan hasil dari proses belajar yang diikuti mahasiswa baik dari dalam kelas maupun luar kelas. Proses belajar merupakan proses perubahan interaksi individu dengan lingkungannya sehingga menghasilkan perubahan yang positif seperti peningkatan pengetahuan, keterampilan dan kompetensi mahasiswa ${ }^{5}$. Prestasi belajar setiap individu berbeda dengan individu lainnya. Prestasi akan memperlihatkan umpan balik dari seluruh hal yang terdiri dari kemampuan, keahlian, kekurangan serta potensi yang dimiliki oleh individu. Pencapaian prestasi belajar ini dapat berupa nilai akhir pada semua mata kuliah yang memperoleh nilai memuaskan dan lulus pada semua mata kuliah ${ }^{6}$. Terdapat beberapa faktor yang

\footnotetext{
${ }^{1}$ Yan Ning dan Jiaojiao Chen, "Improving residential satisfaction of university dormitories through postoccupancy evaluation in China: A socio-technical system approach," Sustainability (Switzerland) 8, no. 10 (2016): 1050-66, https://doi.org/10.3390/su8101050.

2 Anbo Zheng, "Research on the Management Mechanism of the Colleges and Universities Students' Hostel," Advances in Social Science, Education and Humanities Research 63, no. Amahs (2016): 303-6, https://doi.org/10.2991/amahs-16.2016.63.

${ }^{3}$ Claire Reeves La Roche, "Student Housing: Trends, Preferences, and Needs," Contemporary Issues In Education Research 3, no. 10 (2010): 45-50.

${ }^{4}$ Baris Uslu dan Hasan Arslan, "Faculty's Academic Intellectual Leadership : The Intermediary Relations With Universities ' Organizational Components," International Journal of Leadership in Education 10, no. April (2017): 1-13, https://doi.org/10.1080/13603124.2016.1278044; Darren Kwong dan Jonathan Ryan Davis, "School Climate for Academic Success: A Multilevel Analysis of School Climate and Student Outcomes," Journal of Research in Education 25, no. 2 (2015): 68-81; Asep Sunandar dan Ali Imron, "The Model of University Autonomy in Indonesia," Advances in Social Science, Education and Humanities Research 400, no. Icream 2019 (2020): 440-46, https://doi.org/10.2991/coema-19.2019.12.

5 Nikodemus Thomas Martoredjo, "Meningkatkan Prestasi Belajar di Perguruan Tinggi dengan Mengembangkan Kecerdasan Emosional," Humaniora 4, no. 2 (2013): 1093, https://doi.org/10.21512/humaniora.v4i2.3550.

${ }^{6}$ Murdan, Rahmawati, dan Ellen Davita Safaredha, "Prestasi Akademik Dan Non Akademik Mahasiswa Prodi Pendidikan Matematika Angkatan 2012 Fakultas Tarbiyah Dan Keguruan Iain Antasari Banjarmasin," JPM IAIN Antasari 2, no. 1 (2017): 63-72, https://doi.org/10.18592/jpm.v2i1.1167.
} 
mempengaruhi prestasi belajar mahasiswa di dalam kelas berdasarkan teori dan hasil kajian empiris sebelumnya. Selain itu faktor dosen/guru dalam pendidikan juga dapat mempengaruhi prestasi belajar sehingga guru diharapkan dapat merencanakan, melaksanakan proses pembelajaran, dan mengevaluasi pembelajaran. ${ }^{7}$

Dalam meningkatkan prestasi belajar perlu diperhatikan beberapa faktor yaitu faktor internal dan eksternal ${ }^{8}$. Faktor internal meliputi aspek fisiologis (kondisi kesehatan jasmani), aspek psikologis yang meliputi tingkat kecerdasan, sikap, bakat, minat, dan motivasi. Faktor eksternal tmerupakan kondisi di sekitar peserta didik yang terdiri atas lingkungan sosial dan non sosial, metode pembelajaran. Lingkungan sosial meliputi lingkungan sekolah (guru, staf, dan teman-teman) dan lingkungan tempat tinggal (keluarga), sedangkan lingkungan non sosial adalah segala fasilitas penunjang yang dimanfaatkan oleh mahasiswa dalam proses belajar. Selain kedua faktor tersebut faktor ekonomi (keuangan) juga mempengaruhi prestasi belajar mahasiswa penghuni asrama.

Analysis cost effectiveness (analisis efektifitas biaya) merupakan evaluasi yang mempertimbangkan aspek biaya dan konsekuensi dari sebuah alternatif pemecahan masalah. cost effectiveness adalah sebuah alat bantu pembuat keputusan yang dirancang agar pembuat keputusan mengetahui dengan pasti alternatif pemecahan mana yang paling efisien ${ }^{9}$. Sementara menurut ${ }^{10}$ analisis efektifitas biaya ialah model yang digunakan untuk menilai alternatif keputusan yang paling tepat dengan cara membandingkan alternatif tersebut dalam hubungannya dengan keuangan yang harus dikorbankan. Berdasarkan pendapat ahli tersebut, analysis cost effectiveness yakni suatu metode yang mempertimbangan keefektifan suatu nilai dan membandingkannya dengan biaya efektifitas agar dalam pengambilan keputusan tidak terjadi kesalahan. Selain membuat skala prioritas dalam pengaturan keuangan, analysis cost effectiveness dirasa juga cocok untuk mengatur keuangan mahasiswa agar dalam pengambilan keputusan untuk menggunakan uangnya dengan bijak. Mahasiswa yang tinggal di asrama juga perlu menganalisis biaya apa saja yang diperlukan untuk kebutuhan sehari-hari agar keuangan stabil $^{11}$.

Berdasarkan latar belakang diatas menjadi penting untuk diteliti mengenai analisis biaya efektivitas mahasiswa dalam mengatur keuangan dan apakah ada hubungan antara cost effectiveness mahasiswa penghuni asrama terhadap presrtasi belajar. Adapun tujuan dari penelitian ini adalah untuk mengetahui bagaimana hubungan efektifitas biaya yang digunakan dalam asrama dan prioritas antara kebutuhan dan keinginan terhadap hasil belajar yang didapat selama masuk dalam asrama melalui prestasi yang diperoleh baik

\footnotetext{
${ }^{7}$ Mohammad Muchlis Solichin, "MANAJEMEN PEMBELAJARAN PENDIDIKAN ISLAM MODERAT DI PERGURUAN TINGGI ISLAM (Studi Atas Institute Agama Islam Negeri Madura)," re-JIEM (Research Journal of Islamic Education Management) 1, no. 2 (2019): 45, http://ejournal.iainmadura.ac.id/index.php/re-jiem/article/view/2091.

8 Rahardian Okta Pratama, Lindawati Kartika, dan Andita Sayekti, “Analisis Faktor-Faktor Yang Memengaruhi Prestasi Mahasiswa Di Perguruan Tinggi," Perspektif Ilmu Pendidikan 32, no. 2 (2018): 15363, https://doi.org/10.21009/pip.322.8.

${ }^{9}$ Henry M. Levin dan Clive Belfield, "Guiding the Development and Use of Cost-Effectiveness Analysis in Education," Journal of Research on Educational Effectiveness 8, no. 3 (2015): 400-418, https://doi.org/10.1080/19345747.2014.915604.

${ }^{10}$ H F Ladd dan M E Goertz, "Handbook of Research in Education Finance and Policy, Second Edition" (London: Routledge, 2015), https://doi.org/10.4324/9780203788684.

${ }^{11}$ Levin dan Belfield, "Guiding the Development and Use of Cost-Effectiveness Analysis in Education."
} 
dalam aspek akademik maupun non akademik dengan menggunakan metode analisis deskriptif dan analisis uji korelasi.

\section{METODE PENELITIAN}

Pendekatan kuantitatif dengan rancangan penelitian bersifat deskriptif korelasi digunakan dalam penelitian ini. Penelitian kuantitatif digunakan untuk memaparkan kejadian atau fenomena sesuai apa yang terjadi saat penelitian dilaksanakan ${ }^{12}$. Penelitian ini bersifat deskriptif sebab bertujuan untuk mendapatkan gambaran mengenai variabel yang diteliti, bersifat korelasional sebab penelitian ini bertujuan untuk mengetahui ada tidaknya hubungan antara dua variabel atau lebih. Hubungan antar variabel dapat dilihat pada Gambar 1.

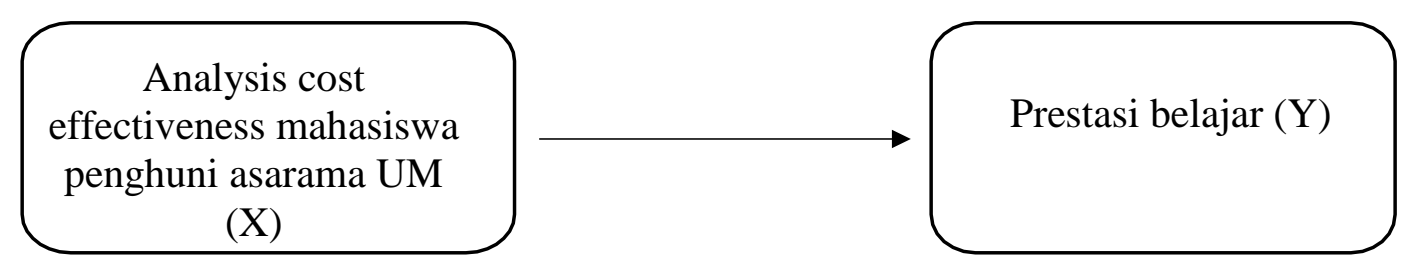

\section{Gambar 1. Hubungan antar Variabel}

Instrumen penelitian yang digunakan dalam penelitian ini adalah angket dengan responden mahasiswa penghuni asrama di fakultas-fakultas lingkungan UM. Responden dalam penelitian sejumlah 46 orang mahasiswa, kemudian pengumpulan data menggunakan bantuan survey google form, instrumen penelitian yang disusun oleh peneliti sebelum digunakan dalam penelitian diuji oleh ahli terlebih dahulu, setelah mendapatkan masukan oleh ahli maka peneliti melanjutkan proses selanjutnya. Berdasarkan masukan tersebut peneliti merevisi instrument dan kemudian digunakan dalam pengumpulan data. Teknik analisis yang digunakan dalam penelitian ini ialah analisis deskriptif dan korelasi. Penelitian ini dalam menganalisis korelasi antara variabel $\mathrm{x}$ dan variabel y menggunakan uji product moment pearson. Penelitian ini dalam melakukan analisis data menggunakan bantuan Statistical Package for Social Science for windows (SPSS) versi 24.

\section{HASIL PENELITIAN DAN PEMBAHASAN}

\section{Cost effectiveness Mahasiswa Penghuni Asrama UM.}

Data yang didapatkan merupakan data tentang cost effectiveness mahasiswa penghuni asrama UM. Data diperoleh dengan instrumen angket menggunakan bantuan google form dengan hasil yang tertera pada Tabel 1. Gambar 2 menunjukkan diagram distribusi frekuensi analisis cost effectiveness mahasiswa penghuni asrama mahasiswa. 12 Bambang Budi Wiyono, Metodologi Penelitian (Pendekatan Kuantitatif, Kualitatif, dan Action
Research), ed. oleh Burhanuddin (Malang: FIP Universitas Negeri Malang, 2007). 
Tabel 1. Distribusi Frekuensi Cost effectiveness Mahasiswa Penghuni Asrama UM.

\begin{tabular}{ccccc}
\hline No & Kategori & Interval & Frekuensi & Prosentase \\
\hline $\mathbf{1}$ & Selalu & $57-63$ & 6 & $13,0 \%$ \\
$\mathbf{2}$ & Sering & $49-56$ & 15 & $32,6 \%$ \\
$\mathbf{3}$ & Jarang & $41-48$ & 19 & $41,3 \%$ \\
$\mathbf{4}$ & Tidak pernah & $33-40$ & 6 & $13,0 \%$ \\
\hline
\end{tabular}

\section{Cost Effectiveness Penghuni Asrama UM}

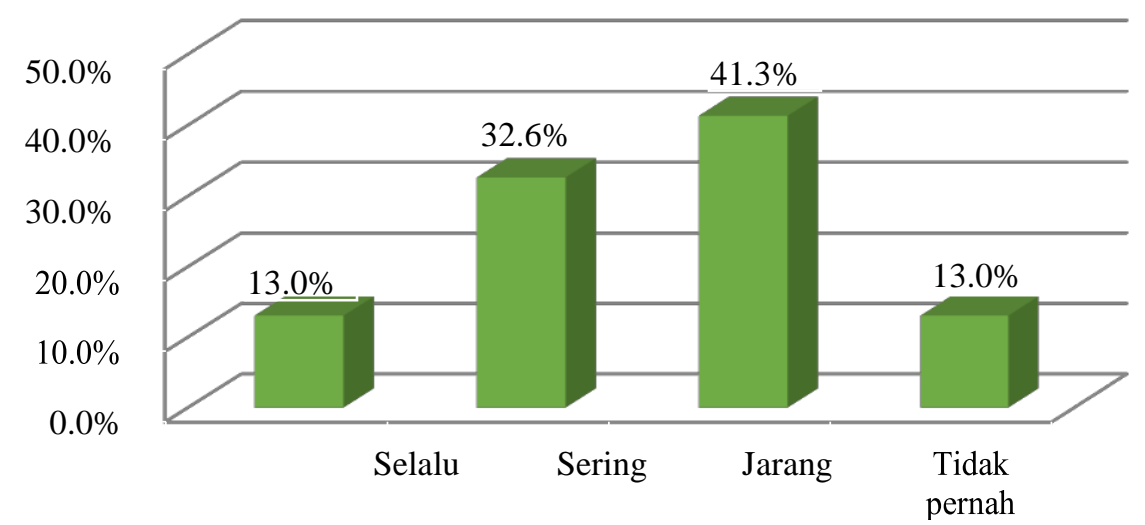

Gambar 2. Diagram distribusi frekuensi Cost effectiveness Mahasiswa Penghuni Asrama UM

Berdasarkan data pada Tabel 1 dan Gambar 2 diketahui bahwa siswa yang mendapatkan total nilai angket pada rentang 57-63 yaitu sebanyak 6 mahasiswa dalam prosentase $13,0 \%$ dengan kategori selalu. Total nilai pada rentang 49-56 yaitu sebanyak 15 mahasiswa dalam prosentase 32,6\% dengan kategori sering. Kemudian total nilai pada rentang 41-48 yaitu sebanyak 19 mahasiswa dalam prosentase 41,3\% dengan kategori jarang, dan terakhir perolehan dengan total nilai pada rentang 33-40 yaitu sebanyak 6 mahasiswa dalam prosentase $13,0 \%$ dengan kategori tidak pernah. Berdasarkan data tersebut dapat disimpulkan mahasiswa penghuni asrama terhitung jarang dalam melakukan analisis cost effectiveness dalam kehidupannya selama menjadi penghuni asrama.

\section{Prestasi Belajar Mahasiswa Penghuni Asrama UM.}

Data yang diperoleh merupakan data tentang prestasi belajar mahasiswa penghuni asrama UM. Data diperoleh dengan instrumen angket dengan hasil yang tertera pada Tabel 2. Gambar 3 menunjukkan diagram distribusi frekuensi prestasi belajar mahasiswa penghuni asrama di lingkungan fakultas-fakultas UM.

Tabel 2. Distribusi Frekuensi Prestasi Belajar Mahasiswa

\begin{tabular}{ccccc}
\hline No & Kategori & Interval & Frekuensi & Presentasi \\
\hline 1 & Sangat baik & $71-84$ & 1 & $2,2 \%$ \\
\hline
\end{tabular}




\begin{tabular}{lcccc}
\hline 2 & Baik & $56-70$ & 1 & $2,2 \%$ \\
3 & Kurang baik & $41-55$ & 24 & $52,2 \%$ \\
4 & Tidak baik & $26-40$ & 20 & $43,5 \%$ \\
\hline
\end{tabular}

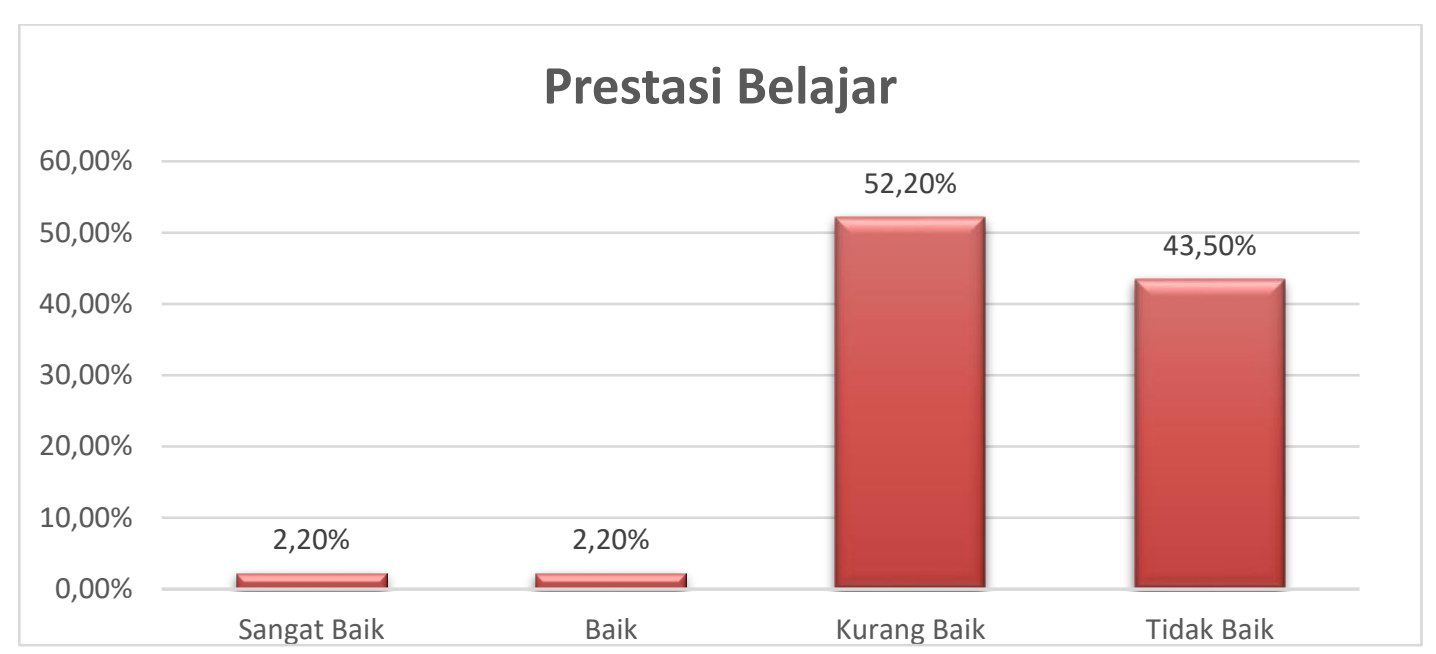

\section{Gambar 3 Prestasi Belajar Mahasiswa Penghuni Asrama UM}

Berdasarkan data pada Tabel 2 dan Gambar 3 diketahui bahwa siswa yang mendapatkan total nilai angket prestasi belajar dengan rentang antara 71-84 yaitu sebanyak 1 mahasiswa dalam prosentase 2,2\% dengan kategori sangat baik. Total nilai pada rentang 56-70 yaitu sebanyak 1 mahasiswa dalam prosentase 2,2\% dengan kategori baik. Kemudian total nilai pada rentang 41-55 yaitu sebanyak 24 mahasiswa dalam prosentase $52,2 \%$ dengan kategori kurang baik, dan terakhir perolehan total nilai pada rentang 26-40 yaitu sebanyak 20 dalam prosentase 43,5\% dengan kategori tidak baik. Berdasarkan data tersebut dapat diartikan tigkat prestasi belajar mahasiswa penhuni asrama di lingkungan UM berada pada kategori kurang baik.

\section{Analisis Hubungan Cost Efectiveness Mahasiswa Penghuni Asrama UM terhadap Prestasi Belajar.}

Pengujian hipotesis menggunakan uji product moment pearson dengan bantuan program SPSS 24.0 for windows. Kriteria pengujian dilakukan dengan cara membandingkan nilai probabilitas $(\mathrm{SIG})<0,05$, artinya Ho ditolak, yang berarti terdapat hubungan yang signifikan antara variabel $\mathrm{x}$ dan variabel $\mathrm{y}^{13}$. Penelitian ini bertujuan untuk menguji apakah ada hubungan antara analisis korelasi cost effectiveness mahasiswa penghuni asrama UM dengan prestasi belajar. Pengujian hipotesis dapat dilihat pada Tabel 3 .

13 Maulana Amirul Adha, Mustiningsih, dan Maisyaroh, "Hubungan Pelaksanaan Sistem Informasi Manajemen Berbasis Komputer Dan Keefektifan Kinerja PNS Di Perguruan Tinggi," Jurnal Administrasi dan Manajemen Pendidikan 1, no. 2 (2018): 124-31, https://doi.org/10.17977/um027v1i22018p124. 
Tabel 3. Uji hipotesis

\begin{tabular}{llll}
\hline Hipotesis & Hasil Uji & Sign & Hasil Pengujian \\
\hline $\begin{array}{l}\text { H0: Tidak terdapat hubungan antara cost } \\
\text { effectiveness penghuni asrama UM dengan } \\
\text { prestasi belajar. }\end{array}$ & 0,000 & 0,050 & $\mathrm{H}_{0}$ ditolak \\
\hline
\end{tabular}

Berdasarkan Tabel 3 dapat diketahui nilai signifikansi sebesar 0,000. Artinya, nilai signifikansi $0,000<0,05$ maka $\mathrm{Ho}$ ditolak, yang berarti Ha diterima yang artinya ada hubungan antara kedua variabel yang signifikan. Hasil tersebut juga menunjukkan bahwa ada hubungan yang bersifat positif dan signifikan yakni apabila variabel analisis cost effectiveness semakin baik dilakukan, maka variabel prestasi belajar mahasiswa penghuni asrama UM juga semakin baik pula.

\section{PEMBAHASAN}

\section{Cost effectiveness Mahasiswa Penghuni Asrama}

Tingkat analysis cost effectiveness mahasiswa penghuni asrama UM yang berada di lingkungan fakultas-fakultas Universitas Negeri Malang, tergolong jarang menggunakan analisis biaya efektifitas untuk mengatur keuangan, hal ini senada dengan hasil prosentase yang menunjukan angka 41,3\%, dapat diketahui bahwa sebagian besar mahasiswa jarang bahkan tidak mengatur keuangannya dengan analisis biaya efektifitas. Hal ini sama dengan konsep kriteria yang digunakan untuk menilai pengelolaan atau manajemen keuangan yang berpedoman pada 5 hal, yakni, tepat guna, tepat waktu, tepat tempat, tepat harga, dan tepat kualitas ${ }^{14}$.

Analysis cost effectiveness dilakukan untuk mengatur kebutuhan kuliah dan kebutuhan sehari-hari. Pengelolaan dan keputusan keuangan diartikan sebagai proses memilih alternatif tertentu dari sejumlah alternatif. Sedangkan, analysis cost effectiveness merupakan suatu metode yang mempertimbangan keefektifan suatu nilai dan membandingkannya dengan biaya efektifitas agar dalam pengambilan keputusan tidak terjadi kesalahan ${ }^{15}$. Artinya, analysis cost effectiveness dalam pengambilan keputusan harus membandingkan biaya efektivitas suatu nilai sebelum mengambil keputusan.

Namun, berdasarkan hasil penelitian ini, mahasiswa menganggap bahwa dalam pengelolaan keuangan mahasiswa penghuni asrama UM tidak terlalu memerlukan analisis yang begitu rumit untuk mengelola keuangan, yakni skala prioritas dalam mengelola keuangan kebutuhan sehari-hari, kebutuhan kuliah dan kebutuhan asrama dirasa lebih cocok dibanding analysis cost effectiveness. Hal ini sejalan dengan pendapat 16 skala prioritas merupakan urutan kebutuhan berdasarkan urutan tingkat

\footnotetext{
${ }^{14}$ Stuart S. Yeh, "The Cost Effectiveness of 22 Approaches for Raising Student Achievement," Journal of Education Finance 36, no. 1 (2010): 38-75, https://doi.org/10.1353/jef.0.0029.

15 Stephanie Riegg Cellini dan James Edwin Kee, "Cost-Effectiveness and Cost-Benefit Analysis," in Handbook of Practical Program Evaluation: Fourth Edition (San Francisco, Ca: Jossey-Bass A Wiley Imprint, 2015), https://doi.org/10.1002/9781119171386.ch24.

16 Andriana Nuralisa, Machmuroch, dan Selly Astriana, "Hubungan antara Adversity Quotient dan Dukungan Sosial Teman Sebaya dengan Penyesuaian Diri Mahasiswa Perantauan Tahun Pertama Fakultas Teknik Universitas Sebelas Maret Surakarta," Wacana 8, no. 2 (2014): 1-12.
} 
kepentingannya. Berdasarkan pendapat tersebut dalam mengelola keuangan, mahasiswa hanya perlu mengurutkan kebutuhan berdasarkan tingkat kepentinganya dan membuat skala prioritas.

\section{Prestasi belajar}

Tingkat prestasi belajar mahasiswa yang berada di lingkungan fakultas-fakultas Universitas Negeri Malang, tergolong kurang baik. Hal ini senada dengan hasil prosentase yang menunjukan angka $52,2 \%$, yang menunjukan prestasi belajar dari mahasiswa penghuni asrama masih rendah. Terdapat dua faktor yang mempengaruhi prestasi belajar pada mahasiswa yakni faktor internal dan eksternal ${ }^{17}$. Faktor internal meliputi aspek fisiologis (kondisi kesehatan jasmani), aspek psikologis yang meliputi tingkat kecerdasan, sikap, bakat, minat, dan motivasi. Faktor eksternal merupakan kondisi di sekitar individu yang terdiri atas lingkungan sosial dan non sosial, metode pembelajaran. Lingkungan sosial meliputi lingkungan sekolah (guru, staf, dan teman sebaya) dan lingkungan tempat tinggal (keluarga), sedangkan lingkungan non sosial adalah segala fasilitas penunjang yang digunakan oleh siswa dalam proses belajar.

Prestasi belajar dapat di bagi menjadi 2 yaitu prestasi akademik dan non akademik, hal ini sesuai dengan pendapat yang dikemukakan oleh ${ }^{18}$, prestasi akademik mahasiswa adalah sebuah proses yang dilakukan oleh mahasiswa untuk memperoleh dan mencapai tujuan yang diinginkan atau dalam hal ini yaitu nilai akademik, yang diikuti oleh mahasiswa selama masa perkuliahan. Sedangkan, prestasi non akademik adalah prestasi atau kemampuan yang dicapai siswa dari kegiatan diluar jam pelajaran atau dapat disebut dengan kegiaran ekstrakurikuler. Prestasi belajar dalam dunia pendidikan sangat diutamakan, apalagi nilai akademik mahasiswa. Nilai akademik mahasiswa disebut IPK, Indeks prestasi (IP) adalah nilai kredit rata-rata yang merupakan satuan nilai akhir yang menggambarkan mutu penyelesaian suatu progam pendidikan pada satu semester. Indeks prestasi dihitung pada setiap akhir semester dan pada akhir progam pendidikan yang hasilnya disebut IP Kumulatif (IPK). IPK singkatan dari Indeks Prestasi Kumulatif merupakan ukuran kemampuian mahasiswa sampai pada periode tertentu yang dihitung berdasarkan jumklah SKS (Satuan Kredit Semester) tiap mata kuliah yang telah ditempuh. Sedangkan, prestasi non akademik didapat dengan mengikuti kegiatan kampus, seperti aktif organisasi dan mengikuti UKM (unit aktivitas kampus).

\section{Hubungan Analysis Cost Effectiveness Mahasiswa Penghuni Asrama UM dan Prestasi Belajar}

Hasil pada analisis korelasi cost effectiveness mahasiswa penghuni asrama UM dengan prestasi belajar berdasakan pengujian hipotesis menunjukkan hasil ada hubungan yang bersifat positif dan signifikan yakni apabila variabel analisis cost effectiveness

\footnotetext{
17 Pratama, Kartika, dan Sayekti, “Analisis Faktor-Faktor Yang Memengaruhi Prestasi Mahasiswa Di Perguruan Tinggi."

18 Herbert W. Marsh dan Andrew J. Martin, "Academic Self-Concept and Academic Achievement: Relations and Causal ordering," British Journal of Educational Psychology 81, no. Maret (2011): 59-77, https://doi.org/10.1348/000709910X503501; Norasyikin Omar, Mimi Mohaffyza Mohamad, dan Aini Nazura Paimin, "Dimension of Learning Styles and Students' Academic Achievement," Procedia - Social and Behavioral Sciences 204 (2015): 172-82, https://doi.org/10.1016/j.sbspro.2015.08.130.
} 
semakin baik dilakukan, maka variabel prestasi belajar mahasiswa penghuni asrama UM juga semakin baik pula. Dalam prosesnya pendidikan memerlukan pengorbananpengorbanan yang secara langsung bersentuhan dalam proses pendidikan. Pengorbanan yang dimaksud yakni suatu biaya yang harus dikeluarkan ${ }^{19}$. Biaya yang dikeluarkan ini akan secara langsung bersentuhan dengan komponen mutu pendidikan. Hal ini berdasarkan asumsi pada tingkat aktivitas yang perlu didanai, yakni semakin tinggi tingkat pendidikan maka akan semakin besar pula biaya yang harus dikeluarkan ${ }^{20}$. Hal ini berarti hasil pendidikan hendaknya dimanfaatkan semaksimal mungkin agar dapat memberikan rate of return yang tinggi, sebab biaya pendidikan merupakan pengeluaran pendidikan yang tidak dapat dihindarkan.

Untuk mengetahui efektivitas biaya pendidikan biasanya digunakan metode analisis keefektifan biaya (cost effectiveness analysis) yang memperhitungkan besarnya kontribusi setiap masukan pendidikan terhadap efektifitas pencapaian tujuan pendidikan atau prestasi belajar ${ }^{21}$. Senada dengan hasil penelitian ini yang menunjukkan analisis keefektifan biaya memiliki hubungan yang signifikan terhadap prestasi belajar mahasiswa. Mahasiswa hendaknya mampu menganalisis atau mempertimbangkan biaya yang akan dikeluarkan dalam kehidupan sehari-harinya, artinya mahasiswa dapat mengurangi pengeluaran yang bersifat sekunder atau yang tidak berpengaruh langsung terhadap kesehatan (kehidupannya) dan juga pendidikannya ${ }^{22}$. Mahasiswa yang melakukan analisis keefektifan biaya dapat mengetahui pengeluaran biaya mana saja yang dirasa tidak efektif terhadap pencapaian prestasi dalam pendidikannya. Sehingga dapat mengurangi stress akibat pengorbanan biaya yang sia-sia, dan tentu saja dapat meningkatkan prestasi belajarnya.

\section{KESIMPULAN}

Tingkat analysis cost effectiveness penghuni asrama mahasiswa UM yang berada di semua lingkungan fakultas yang ada di Universitas Negeri Malang tergolong jarang yang menggunakan analisis efektifitas biaya dalam mengatur keuangan untuk keperluan asrama dan pendidikannya. Tingkat prestasi belajar yang tersebar di semua fakultas yang ada di Universitas Negeri Malang cenderung kurang baik. Hasil penelitian menunjukkan bahwa ada hubungan yang positif antara analysis cost effectiveness penghuni asrama mahasiswa UM terhadap prestasi belajar, yang berarti jika analisis efektifitas biaya tinggi maka prestasi belajar yang dicapai akan tinggi pula.

Berdasarkan kesimpulan, peneliti memberikan saran yang pertama, kepada mahasiswa agar lebih mengatur keuangan untuk kepentingan asrama maupun kuliah. Sehingga mampu memilih atau memprioritaskan keperluan antara asrama, kuliah, dan pribadi. Selain itu, mahasiswa harus mengetahui efektifitas biaya yang digunakan selama di asrama, karena efektifitas biaya mempunyai pengaruh yang signifikan dan hubungan

\footnotetext{
${ }^{19}$ W.P Ferdi, "Pembiayaan Pendidikan: Suatu Kajian Teoritis," Jurnal Pendidikan dan Kebudayaan 19, no. 4 (2013): 565-78.

${ }^{20}$ Nanang Fattah, Sistem Penjaminan Mutu Pendidikan dalam Konteks Penerapan MBS (Bandung: Remaja Rosdakarya, 2013).

${ }^{21}$ Levin dan Belfield, "Guiding the Development and Use of Cost-Effectiveness Analysis in Education."

${ }^{22}$ Ceri Phillips Thompson, "What is Cost-Effectiveness?," Education for health 24, no. 3 (2011): 573, https://doi.org/10.1007/s00383-011-3028-8; Ning dan Chen, "Improving residential satisfaction of university dormitories through post-occupancy evaluation in China: A socio-technical system approach.”
} 
yang positif terhadap prestasi belajar mahasiswa jika dapat dilakukan dengan baik. terlepas dalam hal itu, peneliti juga memberikan saran agar mahasiswa lebih meningkatkan rasa kepedulian dan saling tolong menolong sesama teman dalam asrama agar memudahkan mahasiswa itu sendiri dan teman yang lain ketika belajar.

Dengan kata lain mahasiswa juga harus meningkatkan kemampuan dalam belajar ketika di asrama maupun ketika kuliah agar mampu meningkatkan prestasi belajar. Kemudian untuk yang kedua, yaitu peneliti lain hendaknya dapat membantu mengembangkan penelitian ini dengan cara menemukan permasalahan dan kendala lain yang terdapat dalam analysis cost effectiveness penghuni asrama mahasiswa terhadap prestasi belajar serta dapat mencari solusi dari permasalahan atau kendala tersebut.

\section{DAFTAR PUSTAKA}

Adha, Maulana Amirul, Mustiningsih, dan Maisyaroh. "Hubungan Pelaksanaan Sistem Informasi Manajemen Berbasis Komputer Dan Keefektifan Kinerja PNS Di Perguruan Tinggi." Jurnal Administrasi dan Manajemen Pendidikan 1, no. 2 (2018): 124-31. https://doi.org/10.17977/um027v1i22018p124.

Cellini, Stephanie Riegg, dan James Edwin Kee. "Cost-Effectiveness and Cost-Benefit Analysis." In Handbook of Practical Program Evaluation: Fourth Edition. San Francisco, Ca: Jossey-Bass A Wiley Imprint, 2015. https://doi.org/10.1002/9781119171386.ch24.

Fattah, Nanang. Sistem Penjaminan Mutu Pendidikan dalam Konteks Penerapan MBS. Bandung: Remaja Rosdakarya, 2013.

Ferdi, W.P. "Pembiayaan Pendidikan: Suatu Kajian Teoritis." Jurnal Pendidikan dan Kebudayaan 19, no. 4 (2013): 565-78.

Kwong, Darren, dan Jonathan Ryan Davis. "School Climate for Academic Success: A Multilevel Analysis of School Climate and Student Outcomes." Journal of Research in Education 25, no. 2 (2015): 68-81.

Ladd, H F, dan M E Goertz. "Handbook of Research in Education Finance and Policy, Second Edition." London: Routledge, 2015. https://doi.org/10.4324/9780203788684.

Levin, Henry M., dan Clive Belfield. "Guiding the Development and Use of CostEffectiveness Analysis in Education." Journal of Research on Educational $\begin{array}{lllll}\text { Effectiveness } & 8, & \text { no. } & 3 & \text { (2015): }\end{array}$ https://doi.org/10.1080/19345747.2014.915604.

Marsh, Herbert W., dan Andrew J. Martin. "Academic Self-Concept and Academic Achievement: Relations and Causal ordering." British Journal of Educational Psychology 81, no. Maret (2011): https://doi.org/10.1348/000709910X503501.

Martoredjo, Nikodemus Thomas. "Meningkatkan Prestasi Belajar di Perguruan Tinggi dengan Mengembangkan Kecerdasan Emosional." Humaniora 4, no. 2 (2013): 1093. https://doi.org/10.21512/humaniora.v4i2.3550. 
Murdan, Rahmawati, dan Ellen Davita Safaredha. "Prestasi Akademik Dan Non Akademik Mahasiswa Prodi Pendidikan Matematika Angkatan 2012 Fakultas Tarbiyah Dan Keguruan Iain Antasari Banjarmasin." JPM IAIN Antasari 2, no. 1 (2017): 63-72. https://doi.org/10.18592/jpm.v2i1.1167.

Ning, Yan, dan Jiaojiao Chen. "Improving residential satisfaction of university dormitories through post-occupancy evaluation in China: A socio-technical system approach." Sustainability (Switzerland) 8, no. 10 (2016): 1050-66. https://doi.org/10.3390/su8101050.

Nuralisa, Andriana, Machmuroch, dan Selly Astriana. "Hubungan antara Adversity Quotient dan Dukungan Sosial Teman Sebaya dengan Penyesuaian Diri Mahasiswa Perantauan Tahun Pertama Fakultas Teknik Universitas Sebelas Maret Surakarta." Wacana 8, no. 2 (2014): 1-12.

Omar, Norasyikin, Mimi Mohaffyza Mohamad, dan Aini Nazura Paimin. "Dimension of Learning Styles and Students' Academic Achievement." Procedia - Social and $\begin{array}{llll}\text { Behavioral Sciences } & 204 & \text { (2015): }\end{array}$ https://doi.org/10.1016/j.sbspro.2015.08.130.

Pratama, Rahardian Okta, Lindawati Kartika, dan Andita Sayekti. "Analisis FaktorFaktor Yang Memengaruhi Prestasi Mahasiswa Di Perguruan Tinggi." Perspektif Ilmu Pendidikan 32, no. 2 (2018): 153-63. https://doi.org/10.21009/pip.322.8.

Roche, Claire Reeves La. "Student Housing: Trends, Preferences, and Needs." Contemporary Issues In Education Research 3, no. 10 (2010): 45-50.

Solichin, Mohammad Muchlis. "MANAJEMEN PEMBELAJARAN PENDIDIKAN ISLAM MODERAT DI PERGURUAN TINGGI ISLAM (Studi Atas Institute Agama Islam Negeri Madura)." re-JIEM (Research Journal of Islamic Education Management) 1, no. 2 (2019): 60-69. http://ejournal.iainmadura.ac.id/index.php/rejiem/article/view/2091.

Sunandar, Asep, dan Ali Imron. "The Model of University Autonomy in Indonesia." Advances in Social Science, Education and Humanities Research 400, no. Icream 2019 (2020): 440-46. https://doi.org/10.2991/coema-19.2019.12.

Thompson, Ceri Phillips. "What is Cost-Effectiveness?" Education for health 24, no. 3 (2011): 573. https://doi.org/10.1007/s00383-011-3028-8.

Uslu, Baris, dan Hasan Arslan. "Faculty's Academic Intellectual Leadership: The Intermediary Relations With Universities ' Organizational Components." International Journal of Leadership in Education 10, no. April (2017): 1-13. https://doi.org/10.1080/13603124.2016.1278044.

Wiyono, Bambang Budi. Metodologi Penelitian (Pendekatan Kuantitatif, Kualitatif, dan Action Research). Diedit oleh Burhanuddin. Malang: FIP Universitas Negeri Malang, 2007.

Yeh, Stuart S. "The Cost Effectiveness of 22 Approaches for Raising Student Achievement." Journal of Education Finance 36, no. 1 (2010): 38-75. https://doi.org/10.1353/jef.0.0029. 
Zheng, Anbo. "Research on the Management Mechanism of the Colleges and Universities Students' Hostel." Advances in Social Science, Education and Humanities Research 63, no. Amahs (2016): 303-6. https://doi.org/10.2991/amahs-16.2016.63. 